\title{
TINJAUAN LITERATUR:TERAPI SPIRITUAL (DOA DAN RELAKSASI) UNTUK PASIEN DIABETES MELLITUS TIPE 2
}

\author{
Martha Gita Ongebele, Raimonda Amayu Ida Vitani, Niken Setyaningrum \\ STIKes St. Elisabeth Semarang \\ raimonda.ida@gmail.com
}

\begin{abstract}
Abstrak
Diabetes Mellitus merupakan suatu kelainan metabolik dari distribusi glukosa yang tidak bisa menghasilkan hormon insulin secara optimal sehingga meningkatkan kadar glukosa darah. Penatalaksanaan pada pasien diabetes selain terapi farmakologi ada juga terapi non farmakologi yaitu terapi komplementer dalam hal ini terapi spiritual doa dan relaksasi. Terapi spiritual memberikan efek relaksasi yang dapat menurunkan produksi hormon kortisol dan hormon epinefrin sehingga dapat meningkatkan hormon endorfin untuk menurunkan gula darah pada pasien diabetes mellitus tipe 2. Studi ini bertujuan untuk mengetahui terapi spiritual (doa dan relaksasi) pada pasien Diabetes Mellitus tipe 2. Metode yang digunakan adalah literature review. Pencarian artikel didapatkan dari Google scholar dan Google search dalam rentang waktu tahun 2010 sampai tahun 2020. Pencarian artikel disesuaikan dengan kriteria inklusi dan ekslusi, kemudian dilakukan review. Artikel yang direview adalah artikel tentang terapi spiritual doa dan relaksasi pada pasien Diabetes Mellitus tipe 2. Terdapat 11 artikel yang masuk kedalam analisa untuk dilakukan tinjauan literatur. Artikel - artikel tersebut menjelaskan manfaat doa dan relaksasi bagi pasien diabetes mellitus tipe 2 yaitu menurunkan gula darah dengan cara menghasilkan efek relaksasi yang dapat menekan produksi hormon kortisol dan meningkatkan hormon endorpin untuk menurunkan gula darah. Terapi spiritual yang terdiri dari doa, sholat, zikir, relaksasi nafas dalam dan relaksi benson dapat menurunkan kadar gula darah pada pasien diabetes mellitus tipe 2 .
\end{abstract}

Kata Kunci: Terapi spiritual,doa,relaksasi,zikir,diabetes mellitus tipe 2

\begin{abstract}
Literature Review: Spiritual Healing (Prayer And Relaxation) for Type 2 Diabetes Mellitus. Diabetes Mellitus is a metabolic disorder of glucose distribution that cannot produce the hormone insulin optimally so that it increases blood glucose levels. Management in diabetes patients in addition to pharmacological therapy, there is also nonpharmacological therapy, namely complementary therapy, in this case, spiritual healing, prayer and relaxation. Spiritual therapy provides a relaxing effect which can reduce the production of cortisol and epinephrine hormones so that it can increase endorphins to lower blood sugar in patients with type 2 diabetes mellitus. This study aims to determine spiritual healing (prayer and relaxation) in type 2 Diabetes Mellitus patients. The method used was a literature review. Article searches were obtained from Google scholar and Google search in the period 2010 to 2020. Search for articles was adjusted to inclusion and exclusion criteria, then a review was carried out. The article reviewed is an article that identifies the spiritual therapy of prayer and relaxation in patients with Diabetes Mellitus type 2 and can be accessed in full text. There were 11 articles entered into the analysis for a literature review. These articles explain the benefits of prayer and relaxation for patients with type 2 diabetes mellitus, namely lowering blood sugar by producing a relaxing effect that can suppress the production of the hormone cortisol and increase the endorphin hormone to reduce blood loss. Spiritual healing which consists of prayer, sholat, dhikir, deep breath relaxation and benson relaxation can reduce blood sugar levels in type 2 diabetes mellitus patients.
\end{abstract}

Keywords: Spiritual healing,prayer,relaxation,recitation,Diabetes Mellitus type 2. 


\section{Pendahuluan}

Diabetes Mellitus adalah suatu kelainan metabolik atau metabolic syndrome dari distribusi glukosa yang tidak bisa menghasilkan dan memanfaatkan hormon insulin secara optimal sehingga dapat menyebabkan peningkatan kadar glukosa darah yang melebihi batas normal. (Lakshita, 2017) Diabetes disebut sebagai silent killer karena diabetes bekerja perlahan untuk merusak organ dalam tubuh yang menyebabkan berbagai komplikasi yang mematikan. Diabetes Mellitus merupakan penyakit kronis yang mengancam kesehatan dunia secara serius dan berlangsung seumur hidup. (Kumala Dewi, 2014)

\section{International Diabetes Federation}

(IDF) menyatakan bahwa penderita diabetes didunia pada tahun 2019 berjumlah 9,3\% atau 463 juta orang, dan jumlah ini diproyeksikan mencapai $10,2 \%$ atau 578,4 jutapada tahun 2030, dan pada tahun 2045 akan meningkat menjadi $10,9 \%$ atau 700,2 juta orang. (Internation Diabetes Federation, 2019) World Health Organization (WHO) menyatakan ada 422 juta orang di seluruh dunia hidup dengan penyakit Diabetes dan prevalensinya akan terus meningkat dari tahun ke tahun. (World Health Organization, 2016) Menurut WHO jika diabetes tidak terkontrol dengan baik akan mengakibatkan komplikasi penyakitlainnya. (World Health Organization, 2016)

WHO menyatakan prevalensi penyakit diabetes mellitus di Indonesia pada tahun 2016 yaitu $6,6 \%$ pada laki - laki dan $7,3 \%$ pada perempuan. (World Health Organization, 2016)Indonesia menempati peringkat ketujuh terbesar mengalami penyakit Diabetes dengan jumlah penderita Diabetes yaitu 10 miliar orang. (Internation Diabetes Federation, 2019)Jumlah kematian di Indonesia yang disebabkan oleh penyakit diabetes yaitu 36400 pada laki-laki dan 63000 pada perempuan atau sekitar 6\% dari total kematian. (World Health Organization, 2016)

Riset Kesehatan Dasar Kementerian Kesehatan Republik Indonesia tahun 2018 menyatakan bahwa prevalensi kejadian Diabetes Mellitus yang berusia $\geq 15$ tahun yaitu 2,0 \% atau 713783 orang. (Badan Penelitian dan Pengembangan Kesehatan, 2019) Provinsi Jawa Tengah mencapai 2,1 \% atau 96794 orang. (Badan Penelitian dan Pengembangan Kesehatan, 2019) Usia terbanyak mengalami penyakit Diabetes yaitu pada rentang usia 55-64 yang berjumlah 883251 orang. (Badan Penelitian dan Pengembangan Kesehatan, 2019) Berdasarkan data yang didapatkan dari Dinas Kesehatan Provinsi Jawa Tengah, angka kejadian Diabetes Mellitus tahun 2017 sampai dengan tahun 2019 mengalami peningkatan yaitu 21,9\%. (Dinas Kesehatan Kota Semarang, 2018) Prevalensi Diabetes Mellitus Kota Semarang 3,1\% dihitung dari jumlah penduduk usia lebih dari lima belas tahun. (Dinas Kesehatan Kota Semarang, 2018)

Profil Kesehatan Kota Semarang menyatakan bahwa angka kejadian Diabetes Mellitus di Puskesmas Kota Semarang pada tahun 2018 sebanyak 4183 kasus untuk Diabetes tergantung insulin dan 47248 kasus untuk Diabetes tidak tergantung insulin. (Dinas Kesehatan Kota Semarang, 2018) Pada Rumah Sakit di Kota Semarang kasus Diabetes Mellitus untuk tergantung insulin sebanyak 2896 kasus dan diabetes mellitus tidak tergantung insulin sebanyak 6153 kasus. (Dinas Kesehatan Kota Semarang, 2018) Angka kejadian diabetes mellitus di Puskesmas dan Rumah Sakit di Kota Semarang terbanyak adalah diabetes tidak tergantung insulin atau diabetes tipe dua dengan rentang usia 45 sampai 65 tahun sebanyak 4167 kasus. (Dinas Kesehatan Kota Semarang, 2018)

Penatalaksanaan penyakit Diabetes Mellitus ada dua yaitu farmakologis dan non 
farmakologis. Terapi farmakologi dilakukan dengan cara pemberian obat hipoglikemik oral dan injeksi insulin untuk menurunkan kadar glukosa darah. (Aini \& Aridiana, 2016) Terapi non farmakologi merupakan terapi yang dapat dilakukan oleh perawat sebagai pendamping selain dengan konsumsi obat, salah satunya adalah terapi komplementer. (Novieastari, Ibrahimk, et al., 2020) Terapi komplementer selain relaksasi, olahraga, meditasi, musik, herbal salah satunya adalah doa. (Novieastari, Ibrahim, et al., 2020)

Hasil penelitian Lisa di Amerika Serikat yang berjudul penggunaan doa ketenangan pada dewasadengan Diabetes mengatakan bahwa doa merupakan bentuk pelengkap dan obat alternatif yang digunakan sebagai mekanisme untuk menangani diabetes. (Sacco et al., 2011) Menurut hasil penelitian Linda di Amerika menjelaskan bahwa agama atau spiritualitas lebih kuat sebagai sumber daya koping yang mendukung dampak penyakit pada pasien yang sakit daripada sebagai sumber daya resistensi pada orang yang sehat. (Powell et al., 2003) Hasil penelitian Karin di Jerman yang berjudul doa pribadi pada pasien yang menghadapi penyakit mengatakan bahwa doa untuk manajemen penyakit hampir sama dengan doa untuk penyembuhan penyakit fisik dan kemampuan untuk menemukan makna atau sesuatu yang positif dalam penyakit mereka. (Jors et al., 2015) Hasil penelitian Iwan Adrian tentang konsep spiritualitas dan religiusitas dalam konteks keperawatan diabetes mellitus tipe dua menjelaskan bahwa peran konsep Tuhan bagi penderita diabetes sangat menentukan kondisi psikologis yang memberikan ketenangan bagi pasien. (Ardian, 2016) berbagai penelitian telah dilakukan tentang terapi-terapi doa dan relaksasi bagi pasien diabetes melitus. Oleh sebab itu, melalui tinjaun literatur ini, penulis ingin mengetahui terapi spiritual (doa dan relaksasi) pada pasien Diabetes Mellitus tipe 2.

\section{Metode}

Desain studi yang digunakan adalah Literature Review yang merupakan uraian atau deskripsi tentang literature yang relevan dengan bidang atau topik tertentu menggunakan artikel - artikel penelitan yang dicari menggunakan Googlesearch dan Google scholar. Strategi yang digunakan untuk mencari artikel adalah metode PICOS.

Dalam proses pencarian Literature review, peneliti menggunakan kriteria inklusi dan ekslusi. Peneliti menggunakan kriteria inklusi dan ekslusi untuk menyeleksi literatur mana yg akan peneliti gunakan untuk ditinjau. Kriteria inklusi dan ekslusi yang digunakan peneliti, yaitu:

1. Kriteria Inklusi:
a. Artikel dalam bahasa Indonesia dan bahasa Inggris
b. Artikel yang menggunakan quasi experiment dengan kelompok kontrol.
c. Artikel yang diambil merupakan artikel tahun 2010 sampai dengan tahun 2020, full text
d. Intervensi terapi spiritual yang diberikan pada pasien Diabetes Mellitus dengan masalah peningkatan gula darah, stres dan kecemasan.

2. Kriteria Eksklusi:
a. Artikel yang kualitas metodologinya buruk
b. Artikel yang tidak mendeskripsikan intervensi dan metode penelitiannya

\section{Hasil}

Dalam melakukan penelitian ini peneliti melakukan pencarian artikel penelitian nasional dan internasional tentang terapi spiritual doa dan relaksasi, yang dipublikasikan di internet menggunakan aplikasi pencarian Google Scholar dan Googlesearch. Dari hasil pencarian peneliti menemukan 19 artikel. Setelah dilakukan identifikasi lanjut sesuai kriteria inklusi dan eksklusi maka diperoleh 11 artikel. 
Tabel 1. Hasil Studi Literatur

\begin{tabular}{|c|c|c|c|c|c|c|}
\hline $\begin{array}{c}\text { Penulis, } \\
\text { Tahun }\end{array}$ & Negara & Judul Penelitian & $\begin{array}{l}\text { Jenis Terapi } \\
\text { Spiritual }\end{array}$ & Subjek & $\begin{array}{r}\text { Periode } \\
\text { Waktu }\end{array}$ & Hasil Penelitian \\
\hline $\begin{array}{l}\text { Esti,et al, } \\
\text { 2017(Purw } \\
\text { asih et al., } \\
\text { 2017) }\end{array}$ & Indonesia & $\begin{array}{l}\text { Relaksasi Benson } \\
\text { dan Terapi } \\
\text { Murottal Surat Ar- } \\
\text { Rahmaan } \\
\text { menurunkan } \\
\text { kadar glukosa } \\
\text { darah Puasa pada } \\
\text { penderita } \\
\text { Diabetes Melitus } \\
\text { tipe } 2 \text { di } \\
\text { Kecamatan Maos }\end{array}$ & $\begin{array}{l}\text { Relaksasi } \\
\text { Benson }\end{array}$ & 60 & 7 Hari & $\begin{array}{l}\text { Hasil penelitian } \\
\text { menunjukkan } \\
\text { bahwa kombinasi } \\
\text { relaksasi Benson } \\
\text { dan terapi Murottal } \\
\text { pada kelompok } \\
\text { intervensi } \\
\text { dapat menurunkan } \\
\text { kadar glukosa } \\
\text { darah. }\end{array}$ \\
\hline $\begin{array}{l}\text { Diah, et al, } \\
\text { 2018(Ratn } \\
\text { awati et } \\
\text { al., 2018) }\end{array}$ & Indonesia & $\begin{array}{l}\text { Terapi relaksasi } \\
\text { Benson } \\
\text { termodifikasi } \\
\text { efektif } \\
\text { mengontrol gula } \\
\text { darah pada lansia } \\
\text { dengan Diabetes } \\
\text { Mellitus }\end{array}$ & $\begin{array}{l}\text { Relaksasi } \\
\text { Benson }\end{array}$ & 72 & $\begin{array}{l}3 \quad x \text { per } \\
\text { minggu } \\
45 \text { menit }\end{array}$ & $\begin{array}{l}\text { Ada perbedaan } \\
\text { perubahan kadar } \\
\text { gula darah yang } \\
\text { signifikan pada } \\
\text { kelompok } \\
\text { intervensi yang } \\
\text { Diberikan terapi } \\
\text { relaksasi Benson } \\
(p<0,05) .\end{array}$ \\
\hline $\begin{array}{l}\text { Linda, et al, } \\
\text { 2016(Juwita } \\
\text { et al., 2016) }\end{array}$ & Indonesia & $\begin{array}{l}\text { Pengaruh terapi } \\
\text { relaksasi benson } \\
\text { terhadap kadar gula } \\
\text { darah pada lansia } \\
\text { dengan diabetes }\end{array}$ & $\begin{array}{l}\text { Relaksasi } \\
\text { Benson }\end{array}$ & 38 & $\begin{array}{c}7 \text { hari } x \\
20 \text { menit }\end{array}$ & $\begin{array}{l}\text { Relaksasi Benson } \\
\text { dapat menurunkan } \\
\text { kadar gula darah } \\
\text { pada } \\
\text { Lansia dengan } \\
\text { Diabetes Mellitus } \\
\end{array}$ \\
\hline $\begin{array}{l}\text { Siti, et al, } \\
2020(\text { Hasi } \\
\text { na et al., } \\
2020)\end{array}$ & Indonesia & $\begin{array}{l}\text { Penerapan Shalat } \\
\text { dan doa terhadap } \\
\text { pemaknaan hidup } \\
\text { pada pasien Diabetes } \\
\text { Mellitus }\end{array}$ & $\begin{array}{l}\text { Shalat dan } \\
\text { Doa }\end{array}$ & 30 & 30 hari & $\begin{array}{l}\text { Ada pengaruh } \\
\text { shalat dan doa } \\
\text { terhadap } \\
\text { Pemaknaan hidup } \\
\text { yang signifikan } \\
\text { antara pre dan post. }\end{array}$ \\
\hline $\begin{array}{l}\text { Kusnanto, } \\
2017(\text { Kus } \\
\text { nanto, } \\
2013)\end{array}$ & Indonesi & $\begin{array}{l}\text { Meningkatkan respons } \\
\text { osikososial-spiritual } \\
\text { oada pasien }\end{array}$ & $\begin{array}{l}\text { Aplikasi modl } \\
\text { Self care } \\
\text { Manajemen } \\
\text { (Berdoa, } \\
\text { meditasi,relak } \\
\text { sasi) }\end{array}$ & 50 & 3 bulan & $\begin{array}{l}\text { Hasil penelitian } \\
\text { menunjukkan } \\
\text { bahwa koping } \\
\text { penderita lebih } \\
\text { konstruktif,hubung } \\
\text { an interpersonal } \\
\text { meningkat dan } \\
\text { Penderita lebih } \\
\text { bertawakal dalam } \\
\text { menghadapi } \\
\text { penyakit yang } \\
\text { sedang } \\
\text { diderita }\end{array}$ \\
\hline $\begin{array}{l}\text { Habbibura } \\
\text { hman, et } \\
\text { al, } \\
\text { 2018(Seba } \\
\text { gai \& } \\
\text { Kesehatan }\end{array}$ & Indonesia & $\begin{array}{l}\text { Efektivitas terapi } \\
\text { Dzikir terhadap } \\
\text { kadar glukosa darah } \\
\text { pada penderita } \\
\text { Diabetes Melitus tipe } \\
2\end{array}$ & $\begin{array}{l}\text { Terapi } \\
\text { Zikir }\end{array}$ & 34 & $\begin{array}{c}2 \mathrm{x} \\
\text { sehari } \\
\text { selama } 3 \\
\text { hari }\end{array}$ & $\begin{array}{l}\text { Hasil penelitian } \\
\text { yaitu terapi Dzikir } \\
\text { dapat menurunkan } \\
\text { kadar glukosa } \\
\text { darah secara } \\
\text { efektif pada pasien }\end{array}$ \\
\hline
\end{tabular}




\begin{tabular}{lc}
\hline ,2018) Diabetes Mellitus
\end{tabular}

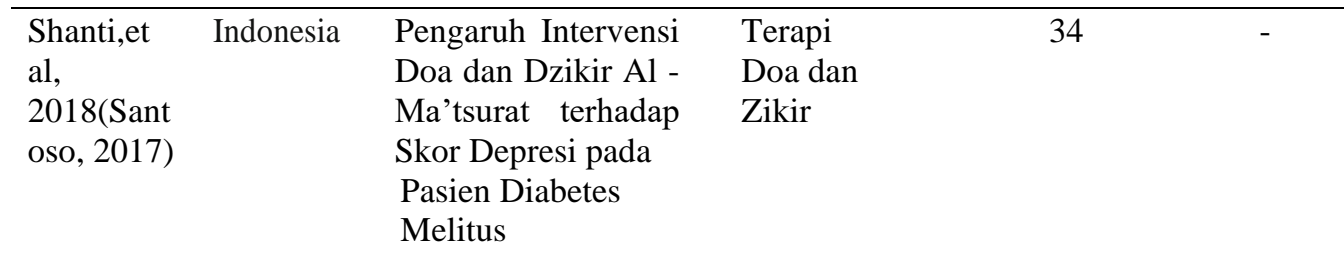

Hasil penelitian ini adalah terdapat Penurunan tingkat stres pada kelompok eksperimen jika dibandingkan dengan kelompok kontrol.

\begin{tabular}{|c|c|c|c|c|}
\hline $\begin{array}{l}\text { Faisal, et Indonesia } \\
\text { al, } \\
\text { 2018(Ami } \\
\text { r et al., } \\
\text { 2018) }\end{array}$ & $\begin{array}{l}\text { Dhikr (recitation) } \\
\text { and relaxation } \\
\text { improve stress } \\
\text { perception and } \\
\text { reduce blood cortisol } \\
\text { level in type } 2 \\
\text { Diabetes Mellitus } \\
\text { patients with ADM }\end{array}$ & $\begin{array}{l}\text { Terapi } \\
\text { Zikir }\end{array}$ & 28 & $\begin{array}{c}6 \\
\text { minggu }\end{array}$ \\
\hline
\end{tabular}

\begin{tabular}{llll}
\hline $\begin{array}{l}\text { Saulia, et } \\
\text { al, }\end{array}$ & Indonesia & Efektivitas relaksasi & Terapi \\
2017(Safit & Zikir untuk & Zikir & 15 \\
ri et al., & menurunkan & \\
n.d.) & tingkat stres pada & \\
& penderita Diabetes & \\
Melitus tipe 2 &
\end{tabular}

Zikir dan relaksasi secara signifikan dapat memperbaiki persepsi stres dengan $\mathrm{p}$ value $(0,001)<0.05$ dan menurunkan kadar kortisol dengan $\mathrm{p}$ value $(0,024)<0.05$ adalah terdapat penurunan tingkat stres pada kelompok eksperimen jika Hasil penelitian ini dibandingkan dengan kelompok kontrol.

\begin{tabular}{|c|c|c|c|c|c|}
\hline $\begin{array}{l}\text { Sabah M, } \\
\text { et al, } \\
2017 \text { (Ebra } \\
\text { hem \& } \\
\text { Masry, } \\
\text { 2017) }\end{array}$ & Mesir & $\begin{array}{l}\text { Effect of } \\
\text { relaxation } \\
\text { therapy on } \\
\text { depression, anxiet } \\
y, \text { stress and } \\
\text { quality of life } \\
\text { among diabetic } \\
\text { patients }\end{array}$ & $\begin{array}{l}\text { Terapi } \\
\text { relaksasi } \\
\text { nafas } \\
\text { dalam }\end{array}$ & 70 & $\begin{array}{l}3 \times \text { sehari } \\
30 \text { menit } / 7 \\
\text { hari }\end{array}$ \\
\hline
\end{tabular}

Relaksasi efektif dalam mengurangi tingkat glukosa darah pada penderita diabetes tipe 2 , menurunkan stres,cemas serta memberi ketenangan.

\begin{tabular}{|c|c|c|c|c|c|c|}
\hline $\begin{array}{l}\text { Lisa, et al, } \\
\text { 2011(Sacc } \\
\text { o et al., } \\
2011 \text { ) }\end{array}$ & US & $\begin{array}{l}\text { Use of the serenity } \\
\text { prayer among adults } \\
\text { with type } 2 \text { diabetes }\end{array}$ & Terapi doa & 36 & $\begin{array}{c}6 \\
\text { minggu }\end{array}$ & $\begin{array}{l}\text { Doa merupakan } \\
\text { bentuk pelengkap } \\
\text { dan obat alternatif } \\
\text { untuk menangani } \\
\text { diabetes yang } \\
\text { memberi } \\
\text { ketenangan. }\end{array}$ \\
\hline
\end{tabular}




\section{Pembahasan}

1. Terapi Spiritual dalam Bentuk Doa Artikel hasil tinjauan literatur tentang terapi spiritual dalam bentuk doa yaitu shalat, doa ketenangan dan terapi zikir yang memiliki manfaat antara lain meningkatkan kalitas hidup, menrunkan tingkat stres, depresi, kecemasan dan zikir yang dpaat menrnkan gula darah, membuat hidup terasa lebih damai, tenang, mendapatkan kekuatan yang mempengaruhi manajemen dalam diabetes. Terapi ini secara umum dilakukan selama lebih dari 30 hari yang dilakukan setiap hari berturut turut.(Amir et al., 2018; Safitri et al., n.d.)

\section{a. Sholat}

Melalui terapi spiritual care berupa sholat mampu membentuk persepsi yang positif berupa keyakinan kepada Tuhan, lebih dekat dengan Tuhan, berserah diri kepada Tuhan sehingga menimbulkan mekanisme koping yang positif, permintaan oksigen meningkat, jantung meningkatkan aliran darah sehingga menimbulkan vasodilatasi pada pembuluh darah, aktivasi gelombang alfa di otak, pelepasan endorphin, serotonin, dopamine, melatonin sehingga terjadi respon adaptif pada diri seseorang untuk lebih menerima suatu penyakit, ikhlas, bersyukur dan memohon ampunan sehingga hasil akhir yang dicapai adalah meningkatnya makna hidup dan kualitas hidup.(Santoso, 2017)

b. Doa

Doa sebagai terapi komplementer dan obat alternatif yang dilakukan mampu membuat hidup terasa lebih damai, tenang, mendapatkan kekuatan yang mempengaruhi manajemen dalam diabetes. (Santoso, 2017)

c. Dzikir

Terapi dzikir yang dilakukan dapat menurunkan gula darah dengan cara memberikan efek relaksasi yang menghambat produksi hormon yang meningkatkan kadar glukosa darah dengan cara menekan kortisol, menghambat metabolisme glukosa (glukoneogenesis) dan menekan pengeluaran glukagon mengkonversi glikogen di hati menjadi glukosa sehingga gula dalam darah menurun.

2. Terapi Spiritual dalam Bentuk Relaksasi

a. Relaksasi Benson

Relaksasi Benson yang dilakukan dapat ,menurunkan gula darah. Relaksasi Benson merupakan perpaduan usaha nafas dalam dan kepercayaan agama yang diselingi dengan permohonan kepada Tuhan Yang Maha Kuasa. Relaksasi Benson dapat menghasilkan frekuensi gelombang alpha pada otak yang menimbulkan perasaan bahagia sehingga dapat menekan pengeluaran hormon kortisol, epinefrin dan norepinefrin yang merupakan vasokontriksi kuat pada pembuluh darah. Proses pernafasan pada relaksasi Benson merupakan proses masuknya $\mathrm{O} 2$ melalui saluran nafas kemudian diedarkan ke seluruh tubuh yang menimbulkan keadaan rileks. Perasaan rileks akan diteruskan ke hipotalamus untuk menghasilkan Corticotropin Releasing Factor (CRF). Selanjutnya CRF merangsang kelenjar di bawah otak untuk meningkatkan 
produksi Proopioidmelanocortin (POMC) sehingga produksi enkephalin oleh medulla adrenal meningkat. Kelenjar di bawah otak juga menghasilkan $\beta$ endorphin sebagai neurotransmitter yang mempengaruhi suasana hati menjadi rileks sehingga gula darah menurun.

b. Relaksasi Nafas Dalam

Relaksasi nafas dalam dalam penelitian ini merupakan perpaduan dari relaksasi otot progresif,relaksasi musik, dan relaksasi imajinasi yang dilakukan dapat menrunkan tingkat depresi, stres dan gula darah yang berpengaruh dalam meningkatkan kualitas hidup pasien diabetes mellitus(Juwita et al., 2016; Purwasih et al., 2017; Ratnawati et al., 2018)

Terapi spiritual dalam bentuk relaksasi dalam tinjauan literatur ini adalah relaksasi Benson dan relaksasi nafas dalam yang merupakan perpaduan dari terapi relaksasi otot progresif, relaksasi musik, dan relaksasi imajinasi yang memiliki banyak manfaat. Manfaat terapi spiritual dalam bentuk relaksasi antara lain menurunkan tingkat depresi, stres, kecemasan dan menurunkan kadar gula dalam darah.Terapi relaksasi Benson merupakan perpaduan relaksasi nafas dan kepercayan agama yang menyatakan penyerahan diri kepada kekuatan tertinggi yaitu Tuhan yang dilakukan berulang untuk mencapai efek dan manfaat yang diharapkan.(Ebrahem \& Masry, 2017)

Berdasarkan kedua bentuk terapi spiritual dalam bentuk doa dan relaksasi diatas, dua terapi tersebut memiliki cara yang sama yaitu dilakukan secara berulang - ulang untuk mencapai efek relaksasi guna mencapai manfaat - manfaat yang diharapkan.

\section{Simpulan dan Saran}

Terapi spiritual terdiri atas terapi doa dan relaksasi, yaitu terapi doa, relaksasi nafas dalam, relaksasi Benson, meditasi, terapi zikir, dan murrotal. Terapi spiritual efektif dalam menurunkan tingkat stres, depresi, meningatkan kualitas hidup dan menurunkan gula darah. Terapi spiritual (doa dan relaksasi) dapat memberikan efek relaksasi yang menghambat produksi hormon yang meningkatkan kadar glukosa darah dan dapat mempengaruhi suasana hati menjadi rileks sehingga gula darah menurun. Melalui hasil literatur ini dapat disarankan kepada pasien DM tipe 2 untuk menggunakan terapi spiritual seperti doa, sholat, relaksasi nafas dalam, meditasi dan zikir untuk membantu menurunkan kadar gula darah. 


\section{Daftar Pustaka}

Aini, N., \& Aridiana, L. M. (2016). Buku Asuhan Keperawatan Pada Sistem Endokrin. In kementrian kesehatan RI (Issue 2001). Salemba Medika.

Amir, F., Mastutik, G., Hasinuddin, M., \& Putra, S. T. (2018). Dhikr (Recitation) and Relaxation Improve Stress Perception and Reduce Blood Cortisol Level in Type 2 Diabetes Mellitus Patients with OAD. Folia Medica Indonesiana, 54(4), 249. https://doi.org/10.20473/fmi.v54i4.107 07

Ardian, I. (2016). Konsep Spiritualitas dan Religiusitas (Spiritual and Religion) dalam Konteks Keperawatan Pasien Diabetes Melitus Tipe 2. Jurnal Keperawatan Dan Pemikiran Ilmiah, 2(5), 1-9.

Badan Penelitian dan Pengembangan Kesehatan. (2019). Laporan Hasil Riset Kesehatan Dasar (Riskesdas) Indonesia tahun 2018. In Riset Kesehatan Dasar 2018 (pp. 127-128). https://www.litbang.kemkes.go.id/lapor an-riset-kesehatan-dasar-riskesdas/

Blonna, richard. (2012). Coping With Stress In A Changing World (M. Ryan (ed.); 5 tahun). William Glass.

Danan Widharsana, P., \& Rudi Hartono, V. (2017). Pengajaan Iman Katolik. Kanisius.

Dinas Kesehatan Kota Semarang. (2018). Profil Kesehatan Kota Semarang 2018. DKK Semarang, 1-104.

Ebrahem, S. M., \& Masry, S. E. (2017). Effect of relaxation therapy on depression, anxiety, stress and quality of life among diabetic patients. Clinical Nursing Studies, 5(1), 35. https://doi.org/10.5430/cns.v5n1p35

Hasina, S. N., Putri, R. A., \& Sulistyorini. (2020). Penerapan Shalat Dan Doa Terhadap Pemaknaan Hidup Pada Pasien Diabetes Mellitus. Jurnal Aini,
N., \& Aridiana, L. M. (2016). Buku Asuhan Keperawatan Pada Sistem Endokrin. In kementrian kesehatan RI (Issue 2001). Salemba Medika.

Amir, F., Mastutik, G., Hasinuddin, M., \& Putra, S. T. (2018). Dhikr (Recitation) and Relaxation Improve Stress Perception and Reduce Blood Cortisol Level in Type 2 Diabetes Mellitus Patients with OAD. Folia Medica Indonesiana, 54(4), 249. https://doi.org/10.20473/fmi.v54i4.107 07

Ardian, I. (2016). Konsep Spiritualitas dan Religiusitas (Spiritual and Religion) dalam Konteks Keperawatan Pasien Diabetes Melitus Tipe 2. Jurnal Keperawatan Dan Pemikiran Ilmiah, 2(5), 1-9.

Badan Penelitian dan Pengembangan Kesehatan. (2019). Laporan Hasil Riset Kesehatan Dasar (Riskesdas) Indonesia tahun 2018. In Riset Kesehatan Dasar 2018 (pp. 127-128). https://www.litbang.kemkes.go.id/lapor an-riset-kesehatan-dasar-riskesdas/

Blonna, richard. (2012). Coping With Stress In A Changing World (M. Ryan (ed.); 5 tahun). William Glass.

Danan Widharsana, P., \& Rudi Hartono, V. (2017). Pengajaan Iman Katolik. Kanisius.

Dinas Kesehatan Kota Semarang. (2018). Profil Kesehatan Kota Semarang 2018. DKK Semarang, 1-104.

Ebrahem, S. M., \& Masry, S. E. (2017). Effect of relaxation therapy on depression, anxiety, stress and quality of life among diabetic patients. Clinical Nursing Studies, 5(1), 35. https://doi.org/10.5430/cns.v5n1p35

Hasina, S. N., Putri, R. A., \& Sulistyorini. (2020). Penerapan Shalat Dan Doa Terhadap Pemaknaan Hidup Pada Pasien Diabetes Mellitus. Jurnal Keperawatan, 12(1), 47-56. 
Internation Diabetes Federation. (2019). IDF Diabetes Atlas Ninth. In Dunia: IDF (2019th ed.). https://diabetesatlas.org/en/sections/wo rldwide-toll-of-diabetes.html

Jors, K., Büssing, A., Hvidt, N. C., \& Baumann, K. (2015). Personal prayer in patients dealing with chronic Illness: A review of the research literature. Evidence-Based Complementary and Alternative Medicine, 2015, 7-8. https://doi.org/10.1155/2015/927973

Juwita, L., Prabasari, N. A., \& Manungkalit, M. (2016). Pengaruh Terapi Relaksasi Benson Terhadap Kadar Gula Darah Pada Lansia Dengan Diabetes. 7.

Kumala Dewi, R. (2014). Tetap Sehat Dengan Pengaturan Pola Makan bagi Penderita Diabetes Tipe 2. Imprint AgroMedia Pustaka.

Kusnanto. (2013). Meningkatkan Respons Psikososial-Spiritual Pada Pasien Diabetes Melitus TIPE 2 Melalui Aplikasi Model Self Care Management. Jurnal Ners, 8(1), 47-55.

Lakshita, N. (2017). Anak Aktif Bebas Diabetes. PT.Buku Kita.

Novieastari, E., Ibrahim, K., Deswani, \& Ramdaniyati, S. (2020). Dasar-Dasar Keperawatan Volume 2 (9th ed.). Elsevier.

Novieastari, E., Ibrahimk, K., Deswani, \& Ramdaniati, S. (2020). Dasar-Dasar Keperawatan Volume 1. Elsevier.

Powell, L. H., Shahabi, L., \& Thoresen, C. E. (2003). Religion and Spirituality: Linkages to Physical Health. American Psychologist, 58(1), 36-52. https://doi.org/10.1037/0003066X.58.1.36
Purwasih, E. O., Permana, I., \& Primanda, Y. (2017). Relaksasi Benson Dan Terapi Murottal Surat Ar-Rahmaan Menurunkan Kadar Glukosa Darah Puasa Pada Penderita Diabetes Melitus Tipe 2 Di Kecamatan Maos. Jurnal Ilmiah Kesehatan Keperawatan, 13(2). https://doi.org/10.26753/jikk.v13i2.211

Ratnawati, D., Siregar, T., \& Wahyudi, C. T. (2018). Terapi Relaksasi Benson Termodifikasi Efektif Mengontrol Gula Darah pada Lansia dengan Diabetes Mellitus. Jurnal Kedokteran Dan Kesehatan, 14(2), 83-93.

Sacco, L. M., Griffin, M. T. Q., McNulty, S. R., \& Fitzpatrick, J. J. (2011). Use of the serenity prayer among adults with type 2 diabetes: A pilot study. Holistic Nursing Practice, 25(4), 192-198. https://doi.org/10.1097/HNP.0b013e31 $822273 \mathrm{a} 8$

Safitri, S., Nashori, H. F., \& Sulistyarini, I. (n.d.). Tingkat Stres Pada Penderita Diabetes Melitus Tipe II Relaxation With Dhikr To Decrease Stress Among Type II Diabetes Patients. 9(1), 1-15.

Santoso, T. (2017). Nursing Practices Nursing. 1(3), 133-139.

Sebagai, M., \& Kesehatan, P. (2018). Jurnal Ners LENTERA, Vol. 6, No. 1, Maret 2018. Kesehatan, 6(1), 49-54. http://repository.wima.ac.id/18138/2/2Literatur_Review_Efektivitas_.pdf

World Health Organization. (2016). Proportional mortality (\% of total deaths, all ages). World Health Organization, 1. https:/www.who.int/diabetes/countryprofiles/bra_en.pdf 